\title{
Implantation techniques (predilatation, sizing, and post- dilatation) and the incidence of scaffold thrombosis and revascularisation in lesions treated with an everolimus- eluting bioresorbable vascular scaffold: insights from the AIDA trial
}

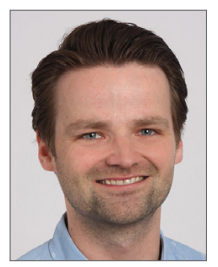

Ruben Y.G. Tijssen ${ }^{1}$, MD; Robin P. Kraak ${ }^{1}$, MD; Joelle Elias ${ }^{1}$, MD; Ivo M. van Dongen ${ }^{1}$, MD; Deborah N. Kalkman ${ }^{1}$, MD; Martina Nassif ${ }^{1}$, MD; Yohei Sotomi ${ }^{1}$, MD; Taku Asanoํ, MD; Yuki Katagiri ${ }^{1}, \mathrm{MD}$; Carlos Collet ${ }^{1}, \mathrm{MD}$; Jan J. Piek ${ }^{1}, \mathrm{MD}$, PhD; Jose P. Henriques ${ }^{1}, \mathrm{MD}, \mathrm{PhD}$; Robbert J. de Winter ${ }^{1}, \mathrm{MD}$, PhD; Jan G.P. Tijssen ${ }^{1}$, PhD; Yoshinobu Onuma ${ }^{2,3}, \mathrm{MD}, \mathrm{PhD}$; Patrick W. Serruys ${ }^{4}, \mathrm{MD}, \mathrm{PhD}$; Joanna J. Wykrzykowska ${ }^{1 *}, \mathrm{MD}, \mathrm{PhD}$

1. AMC Heartcenter, Academic Medical Center - University of Amsterdam, Amsterdam, the Netherlands; 2. Cardialysis BV, Rotterdam, the Netherlands; 3. Erasmus MC, Rotterdam, the Netherlands; 4. Imperiat College London, London, United Kingdom Ruben Y.G. Tijssen and Robin P. Kraak contributed equally to this manuscript.

GUEST EDITORS: Adnan Kastrati, MD; Deutsches Herzzentrum, Munich, Germany, and Alec Vahanian, MD, PhD; Department of Cardiology, Hôpital Bichat-Claude Bernard and University Paris VII, Paris, France

This paper also includes supplementary data published online at: http://www.pcronline.com/eurointervention/137th_issue/77

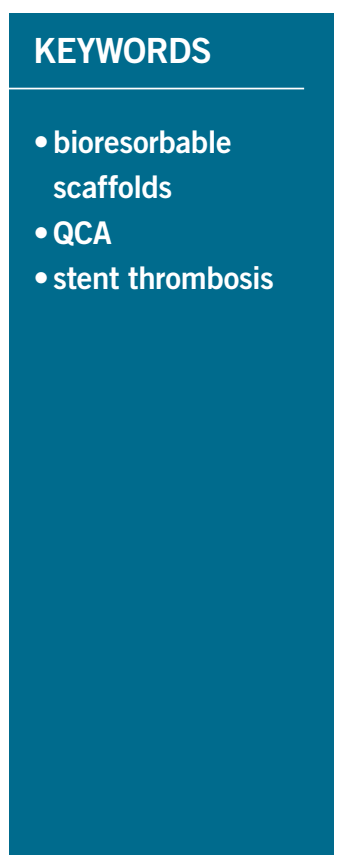

\begin{abstract}
Aims: Specific implantation strategies have been proposed for the Absorb bioresorbable vascular scaffold (Absorb BVS) to optimise outcomes. We aimed to analyse whether the occurrence of definite scaffold thrombosis (ScT) and target lesion revascularisation (TLR) in Absorb-treated AIDA patients was influenced by scaffold implantation techniques.
\end{abstract}

Methods and results: Absorb BVS implantation in 1,074 lesions was graded according to definitions of optimal implantation based on predilatation, sizing, and post-dilatation (PSP). Lesion-oriented outcomes (definite ScT and TLR) that occurred during a median follow-up of 707 days were related to the presence or absence of PSP. Of 1,074 lesions, 158 (14.7\%) lesions met PSP criteria. The most prevalent reason for not meeting PSP criteria was inadequate sizing: 863 (94.2\%). Definite ScT occurred in four of 158 PSP-treated lesions compared with 27 of 916 non PSP-treated lesions, with two-year KM estimates of 3.0\% vs. $4.1 \%$ and an HR of 1.14 ( $\mathrm{p}=0.811$ ). TLR occurred in eight of 158 PSP-treated lesions compared with 61 of 916 non PSP-treated lesions, with KM estimates of 5.6\% vs. $7.1 \%$ and an HR of 1.29 ( $\mathrm{p}=0.492$ ).

Conclusions: In AIDA, lesions that underwent scaffold implantation according to an optimised Absorb BVS implantation technique did not have lower rates of ScT and TLR compared to scaffold-treated lesions that did not meet PSP criteria.

\footnotetext{
*Corresponding author: Department of Cardiology, Academic Medical Center - University of Amsterdam, Meibergdreef 9, 1105 AZ Amsterdam, the Netherlands.E-mail: j.j.wykrzykowska@amc.uva.nl
} 


\section{Abbreviations}

$\begin{array}{ll}\text { DES } & \text { drug-eluting stent } \\ \text { DoCE } & \text { device-orientated composite endpoint } \\ \text { PSP } & \text { predilatation, sizing, post-dilatation } \\ \text { QCA } & \text { quantitative coronary angiography } \\ \text { TLR } & \text { target lesion revascularisation }\end{array}$

\section{Introduction}

Metallic drug-eluting stents (DES) have become the cornerstone of percutaneous coronary intervention (PCI) for the treatment of coronary artery disease. However, they have some shortcomings: the presence of permanent metallic cages prevents arterial healing, impairs vasomotion and may be associated with neoatherosclerosis, incomplete endothelialisation, and polymer hypersensitivity with consequent stent thrombosis ${ }^{1}$. Bioresorbable scaffolds were designed potentially to overcome these remaining shortcomings of metallic DES.

Short-term results of randomised controlled trials comparing the Absorb bioresorbable vascular scaffold (Absorb BVS; Abbott Vascular, Santa Clara, CA, USA) with the XIENCE stent (Abbott Vascular) in non-complex populations were promising and showed acceptable results ${ }^{2-4}$. Long follow-up of these studies raised safety concerns, especially regarding an increased rate of (very) late scaffold thrombosis $(\mathrm{ScT})^{5-8}$. The Amsterdam Investigator-Initiated Absorb Strategy All-comers (AIDA) randomised trial compared the Absorb BVS with the XIENCE in routine $\mathrm{PCI}^{9}$. The preliminary results of the trial were reported due to safety concerns. Up to a median follow-up of 707 days, no significant difference in target vessel failure was demonstrated, but a statistically significantly higher rate of definite or probable Absorb BVS thrombosis occurred as compared to XIENCE (3.5\% vs. $0.9 \%)$.

Previous retrospective studies, with post hoc analysis, have demonstrated that an Absorb BVS-specific implantation technique could reduce the risk of ScT. This specific implantation technique consists of predilatation, sizing, and post-dilatation and is known as the PSP implantation strategy. The objective of our analysis was to investigate the relationship between the PSP implantation technique and subsequent lesion-specific outcomes in the AIDA trial.

Editorial, see page 373

\section{Methods}

\section{THE AIDA TRIAL STUDY DESIGN}

AIDA randomised 1,845 patients undergoing PCI to receive either Absorb BVS or XIENCE. The design ${ }^{10}$ and results ${ }^{11}$ of the trial have been published previously. The trial enrolled patients with coronary artery disease who were undergoing PCI and had one or more target lesions that were considered, on the basis of clinical judgement, to be suitable for DES implantation.

\section{DESIGN OF THE CURRENT ANALYSIS}

The present analysis included lesions that received at least one Absorb BVS for which a baseline angiogram suitable for quantitative coronary angiography (QCA) was available. All Absorb
BVS-treated lesions underwent QCA and were characterised as meeting or not meeting PSP criteria. The occurrence of lesionoriented outcomes (ScT and TLR) was compared between lesions treated in accordance with PSP criteria and those which were not.

QCA was performed for all Absorb BVS-treated lesions with the use of validated offline software (Cardiovascular Angiography Analysis System, version 5.11; Pie Medical Imaging, Maastricht, the Netherlands). Analyses were performed by seven experienced readers, supervised by one QCA expert (Y. Onuma). All readers were blinded to events. Post-procedural angiograms were used to conduct QCA measurements (reference vessel diameter [RVD], minimum lumen diameter and \% diameter residual stenosis), in a single projection. The RVD was taken as an interpolated average between the proximal and distal RVD. If multiple projections were available, the projection with the visually highest grade of stenosis was used.

PSP scoring was established according to the following criteria. Predilatation was scored as "performed" or "not performed". Scaffold sizing in lesions treated with a single scaffold was scored as "correct" if there was a match between scaffold and vessel diameter according to the following criteria: (1) a scaffold with a nominal diameter of $2.5 \mathrm{~mm}$ was implanted in a vessel with an RVD $\geq 2.5 \mathrm{~mm}$ and $<2.75 \mathrm{~mm}$; (2) a scaffold with a nominal diameter of $3.0 \mathrm{~mm}$ was implanted in a vessel with an RVD $\geq 2.75 \mathrm{~mm}$ and $<3.25 \mathrm{~mm}$; or (3) a scaffold with a nominal diameter of $3.5 \mathrm{~mm}$ was implanted in a vessel with an RVD $\geq 3.25 \mathrm{~mm}$ and $<3.75 \mathrm{~mm}$. In lesions in which multiple scaffolds were implanted, we applied three different definitions for correct PSP scaffold sizing: PSP-A (all), PSP-S (single), and PSP-M (mean). Sizing was correct according to PSP-A if all implanted scaffolds were sized correctly, according to PSP-S if at least one single implanted scaffold was sized correctly, and according to PSP-M if the mean nominal diameter of all implanted scaffolds fell within the correct window for the RVD. Post-dilatation was scored as correct if performed with a non-compliant balloon with a nominal diameter equal to or greater than that of the widest scaffold, but no greater than $0.5 \mathrm{~mm}$ over the nominal scaffold diameter.

\section{LESION-ORIENTED OUTCOMES}

The lesion-oriented outcomes of this analysis were definite ScT and target lesion revascularisation (TLR). All outcomes were adjudicated by an independent clinical events committee (Cardialysis B.V., Rotterdam, the Netherlands) according to the definitions of the Academic Research Consortium ${ }^{11}$.

\section{STATISTICAL ANALYSES}

This report provides descriptive information on all lesion-oriented outcomes that occurred before December 2016, subdivided by PSP status. All statistical comparisons were descriptive without formal statistical testing. Event rates were based on Kaplan-Meier (KM) estimates in time-to-first-event analyses. Kaplan-Meier event curves were compared between the PSP groups by means of the log-rank test. Cox regression analysis was used to determine hazard ratios (HR) with $95 \%$ confidence intervals (CI). The Cox 
regression analysis takes lesion-specific outcomes within patients as independent observations. A preliminary analysis, where clustering of lesions within patients was taken into account (a Cox model with patients as a random effect/frailty and PSP status), showed that within a patient correlation was virtually absent $(\mathrm{p}=1.00$ for both TLR and ScT). Follow-up was censored in December 2016, or at the last known event-free time point. We used Fisher's exact test to compare categorical variables and independent t-tests to compare continuous variables. All statistical analyses were performed with SPSS Statistics, Version 23 (IBM Corp., Armonk, NY, USA).

\section{Results POPULATION}

In AIDA, 924 patients were randomised to treatment with the Absorb BVS, of whom 869 were available for this analysis (Figure 1). Of the 1,169 lesions in these patients, 32 were excluded because the lesion was treated with a metallic stent. For another 63 lesions no QCA was available. The final cohort consisted of 1,074 lesions treated with one or more Absorb BVS and a baseline angiography suitable for QCA.

\section{PSP GRADING AND PROCEDURAL CHARACTERISTICS}

Table 1 shows the full PSP scoring of the Absorb BVS-treated lesions. Of the 1,074 lesions, 158 (14.7\%) lesions met PSP-A, 174 (16.2\%) PSP-S, and 162 (15.1\%) PSP-M criteria. The most prevalent reason for not meeting PSP criteria was inadequate sizing. When the analysis was restricted to lesions that were treated with only one scaffold, 131 (14.8\%) of 884 lesions met PSP criteria. Table 2 depicts details of the lesions with inconsistent PSP scores. Full procedural characteristics of the lesions by PSP-A are displayed in Table 3.

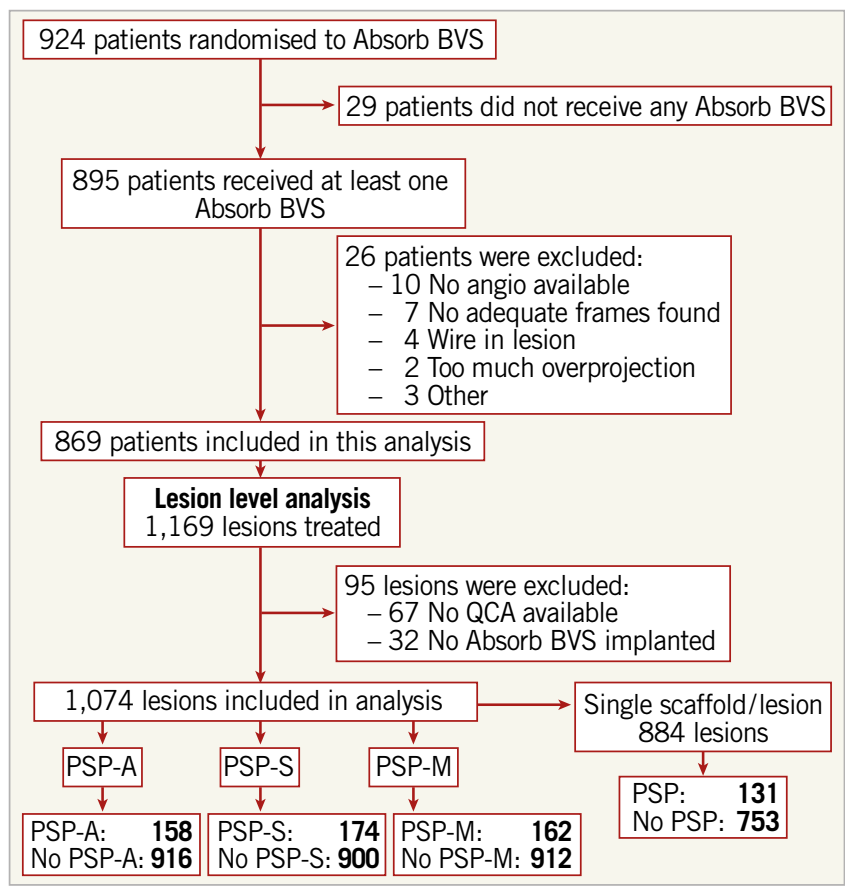

Figure 1. Study flow chart. BVS: bioresorbable vascular scaffold; PSP: predilatation performed, scaffold(s) correctly sized, postdilatation correctly performed; PSP-A: all scaffolds correctly sized; PSP-M: mean scaffold diameter correctly sized; PSP-S: at least one scaffold correctly sized; QCA: quantitative coronary angiography

\section{LESION-ORIENTED OUTCOMES}

Table 4, Figure 2, and Figure 3 show lesion-oriented outcomes by PSP scores. Definite ScT occurred in four of 158 PSP-A treated lesions compared with 27 of the 916 non-PSP-A treated lesions, with two-year KM estimates of $3.0 \%$ vs. $4.1 \%$ and

Table 1. PSP scoring for 1,074 lesions treated with the Absorb scaffold among 869 patients.

\begin{tabular}{|c|c|c|c|c|}
\hline & \multicolumn{3}{|c|}{$\begin{array}{l}\text { All lesions } \\
(n=1,074)\end{array}$} & \multirow{2}{*}{$\begin{array}{l}\text { Lesions with single } \\
\text { scaffold }(n=884) \\
\text { PSP }\end{array}$} \\
\hline & PSP-A & PSP-S & PSP-M & \\
\hline PSP criteria met & 158 & 174 & 162 & 131 \\
\hline PSP criteria not met & 916 & 900 & 912 & 753 \\
\hline \multicolumn{5}{|l|}{ Reasons for no PSP } \\
\hline No predilation performed & 25 & 25 & 25 & 20 \\
\hline Incorrect scaffold sizing & $863(94.2 \%)$ & $824(91.6 \%)$ & $855(93.8 \%)$ & 707 (93.9\%) \\
\hline Scaffold undersized & 63 & 54 & 55 & 50 \\
\hline Scaffold oversized & 803 & 771 & 800 & 657 \\
\hline Scaffold undersized and oversized & 3 & 1 & $\mathrm{n} / \mathrm{a}$ & \\
\hline Incorrect post-dilation & 300 & 300 & 300 & 234 \\
\hline No post-dilation & 258 & 258 & 258 & 213 \\
\hline Undersized post-dilation & 20 & 20 & 20 & 15 \\
\hline Oversized post-dilation & 16 & 16 & 16 & 6 \\
\hline No complete post-dilation & 6 & 6 & 6 & 0 \\
\hline
\end{tabular}

PSP: predilation performed, correctly sized, post-dilation correctly performed; PSP-A: all scaffolds correctly sized; PSP-M: mean Scaffold diameter correctly sized; PSP-S: at least one single scaffold correctly sized 
Table 2. Details of lesions with inconsistent PSP scores.

\begin{tabular}{|l|l|l|l|l|l|l|l|c|c|}
\hline Patient \# & QCA diameter & \# scaffolds & Diameter 1 & Diameter 2 & Diameter 3 & Mean diameter & PSP-A & PSP-S & PSP-M
\end{tabular}

\begin{tabular}{|r|l|l|l|l|l|l|l|l|l|}
\hline 1 & 3.060 & 2 & 3.0 & 3.5 & & 3.25 & 0 & 1 & 0 \\
\hline 2 & 2.862 & 3 & 3.0 & 3.5 & & 3.25 & 0 & 1 \\
\hline 3 & 3.427 & 2 & 3.5 & 3 & & 3.25 & 0 & 1 & 1 \\
\hline 4 & 2.529 & 2 & 3.0 & 2.5 & & 2.75 & 0 & 1 & 0 \\
\hline 5 & 2.736 & 3 & 2.5 & 3.0 & 3.0 & 2.83 & 0 & 1 & 0 \\
\hline 6 & 2.830 & 2 & 2.5 & 3.5 & & 2.75 & 0 & 1 & 1 \\
\hline 7 & 2.845 & 2 & 3.0 & 3.5 & & 3.25 & 0 & 1 & 0 \\
\hline 8 & 2.804 & 2 & 3.5 & 2.5 & & 3.00 & 0 & 0 & 1 \\
\hline 9 & 2.771 & 2 & 3.0 & 3.5 & & 3.25 & 0 & 1 & 0 \\
\hline 10 & 3.089 & 2 & 3.5 & 3.0 & & 3.15 & 0 & 1 & 0 \\
\hline 11 & 2.650 & 3 & 3.0 & 3.0 & 2.5 & 2.83 & 0 & 1 & 0 \\
\hline 12 & 2.904 & 2 & 3.0 & 3.5 & & 3.25 & 0 & 1 & 0 \\
\hline 13 & 2.538 & 2 & 2.5 & 3.0 & & 2.75 & 0 & 1 & 0 \\
\hline 14 & 2.605 & 2 & 2.5 & 3.0 & & 2.75 & 0 & 1 & 0 \\
\hline 15 & 2.509 & 2 & 3.0 & 2.5 & & 2.75 & 0 & 1 & 0 \\
\hline 16 & 2.833 & 2 & 2.5 & 3.0 & & 2.75 & 0 & 1 & 1 \\
\hline 17 & 3.114 & 2 & 3.0 & 3.5 & & 3.25 & 0 & 1 & 0 \\
\hline
\end{tabular}

PSP: predilatation, sizing, post-dilatation; QCA: quantitative coronary angiography

Table 3. Procedural characteristics of 1,074 lesions treated with Absorb scaffold by PSP-A scoring.

\begin{tabular}{|c|c|c|c|c|}
\hline & PSP-A* & No PSP-A & $p$-value \\
\hline \multirow[t]{3}{*}{ Treated lesions } & Total number & 158 & 916 & \\
\hline & Rotational atherectomy, n (\%) & $3(1.9 \%)$ & $19(2.1 \%)$ & 1.000 \\
\hline & Thrombus aspiration, $\mathrm{n}(\%)$ & $9(5.7 \%)$ & $81(8.8 \%)$ & 0.120 \\
\hline Predilatation & Predilatation of the complete lesion performed & $158(100 \%)$ & $891(97.3 \%)$ & 0.039 \\
\hline \multirow[t]{5}{*}{ Device implantation } & Number of devices per lesion & $1.19 \pm 0.45$ & $1.20 \pm 0.46$ & 0.740 \\
\hline & Single device per lesion, $\mathrm{n}(\%)$ & $131(82.9 \%)$ & $754(82.3 \%)$ & 0.910 \\
\hline & Multiple devices per lesion, $\mathrm{n}(\%)$ & $27(17.1 \%)$ & $162(17.7 \%)$ & 0.910 \\
\hline & Device diameter, $\mathrm{mm}$ mean $\pm \mathrm{SD}$ & $3.16 \pm 0.31$ & $3.06 \pm 0.37$ & 0.001 \\
\hline & Total device length, $\mathrm{mm}$ mean $\pm \mathrm{SD}$ & $23.20 \pm 10.97$ & $24.28 \pm 12.50$ & 0.304 \\
\hline \multirow[t]{3}{*}{ Post-dilatation } & Post-dilatation of the complete lesion performed & $158(100 \%)$ & $652(71.2 \%)$ & $<0.001$ \\
\hline & Post-dilatation maximum nominal balloon diameter, mm mean \pm SD & $3.40 \pm 0.40$ & $3.25 \pm 0.44$ & $<0.001$ \\
\hline & Max post-dilatation balloon pressure, atm mean \pm SD & $15.32 \pm 3.41$ & $15.26 \pm 3.66$ & 0.834 \\
\hline \multirow{2}{*}{$\begin{array}{l}\text { Quantitative coronary } \\
\text { angiography analysis }\end{array}$} & Reference vessel diameter & $3.10 \pm 0.31$ & $2.58 \pm 0.44$ & $<0.001$ \\
\hline & Residual stenosis (\%) & $18.12 \pm 8.85$ & $17.02 \pm 9.59$ & 0.182 \\
\hline
\end{tabular}

*PSP-A: predilation performed; all scaffolds correctly sized, if post-dilation was correctly performed. PSP: predilatation, sizing, post-dilatation

an HR of 1.14 (95\% CI: $0.40-3.25 ; \mathrm{p}=0.811)$. TLR occurred in eight of 158 PSP-A treated lesions compared with 61 of 916 non-PSP-A treated lesions, with $\mathrm{KM}$ estimates $5.6 \%$ vs. $7.1 \%$ and an HR of 1.29 (95\% CI: 0.62-2.70; $\mathrm{p}=0.492$ ). Half of the TLRs were associated with ScT. There was one more case of ScT and TLR in PSP-S treated lesions. Results were similar when implantations were graded according to PSP-M criteria. Scaffold sizing and post-dilatation individually were not associated with an increased rate of ScT or TLR (Supplementary Figure 1, Supplementary Figure 2).
When the analysis was restricted to lesions treated with a single scaffold, 131 of 884 (14.8\%) lesions met PSP criteria. Definite ScT occurred in three of 131 PSP-treated lesions against 24 of 753 non-PSP-treated lesions, with two-year KM estimates of $2.9 \%$ vs. $3.3 \%$ and an HR 1.35 (95\% CI: 0.41-4.49; $\mathrm{p}=0.622$ ). TLR occurred in seven of 131 PSP-treated lesions compared with 50 of 753 non-PSP-treated lesions, with two-year KM estimates of $3.1 \%$ vs. $3.8 \%$ and an HR 1.22 (95\% CI: 0.55-2.69; p=0.622). Scaffold sizing and post-dilatation individually were not associated with an increased rate of ScT or TLR (Supplementary 
Table 4. Lesion-specific outcomes of 1,074 lesions treated with Absorb by PSP scoring.

\begin{tabular}{|c|c|c|c|c|c|c|}
\hline & \multicolumn{2}{|c|}{ Patients with event } & \multicolumn{2}{|c|}{ 2-year cum event rate* } & \multirow{2}{*}{$\begin{array}{l}\text { Hazard ratio } \\
(95 \% \text { CI) }\end{array}$} & \multirow{2}{*}{$p$-value ${ }^{\pi}$} \\
\hline & PSP & No PSP & PSP & No PSP & & \\
\hline All lesions according to PSP-A (all scaffolds correct) & $n=158$ & $n=916$ & & & & \\
\hline Definite scaffold thrombosis & 4 & 27 & $3.0 \%$ & $4.1 \%$ & $1.14[0.40-3.25]$ & 0.811 \\
\hline Any target lesion revascularisation & 8 & 61 & $5.6 \%$ & $7.1 \%$ & $1.29[0.62-2.70]$ & 0.492 \\
\hline Target lesion revascularisation without scaffold thrombosis & 4 & 35 & $2.6 \%$ & $4.3 \%$ & $1.48[0.53-4.17]$ & 0.452 \\
\hline All lesions according to PSP-S (single scaffold correct) & $n=174$ & $\mathrm{n}=900$ & & & & \\
\hline Definite scaffold thrombosis & 5 & 26 & $2.9 \%$ & $2.9 \%$ & $0.98[0.38-2.56]$ & 0.972 \\
\hline Any target lesion revascularisation & 9 & 60 & $5.6 \%$ & $8.1 \%$ & $1.25[0.62-2.52]$ & 0.502 \\
\hline Target lesion revascularisation without scaffold thrombosis & 4 & 35 & $2.4 \%$ & $4.4 \%$ & $1.67[0.59-4.69]$ & 0.328 \\
\hline All lesions according to PSP-M (mean scaffold correct) & $n=162$ & $n=912$ & & & & \\
\hline Definite scaffold thrombosis & 4 & 27 & $3.0 \%$ & $3.1 \%$ & $1.17[0.41-3.34]$ & 0.770 \\
\hline Any target lesion revascularisation & 8 & 61 & $5.4 \%$ & $7.1 \%$ & $1.33[0.64-2.78]$ & 0.445 \\
\hline Target lesion revascularisation without scaffold thrombosis & 4 & 35 & $2.5 \%$ & $4.3 \%$ & $1.53[0.54-4.29]$ & 0.420 \\
\hline Lesions treated with a single scaffold according to PSP & $n=131$ & $n=753$ & & & & \\
\hline Definite scaffold thrombosis & 3 & 24 & $2.9 \%$ & $3.3 \%$ & $1.35[0.41-4.49]$ & 0.622 \\
\hline Any target lesion revascularisation & 7 & 50 & $6.0 \%$ & $8.0 \%$ & 1.22 [0.55-2.69] & 0.622 \\
\hline Target lesion revascularisation without scaffold thrombosis & 4 & 27 & $3.1 \%$ & $3.8 \%$ & $1.16[0.41-3.30]$ & 0.788 \\
\hline
\end{tabular}

* Event rates were based on Kaplan-Meier estimates in time-to-event analyses. " $p$-values, calculated by the log-rank test, are descriptive.

PSP: predilatation, sizing, post-dilatation

A

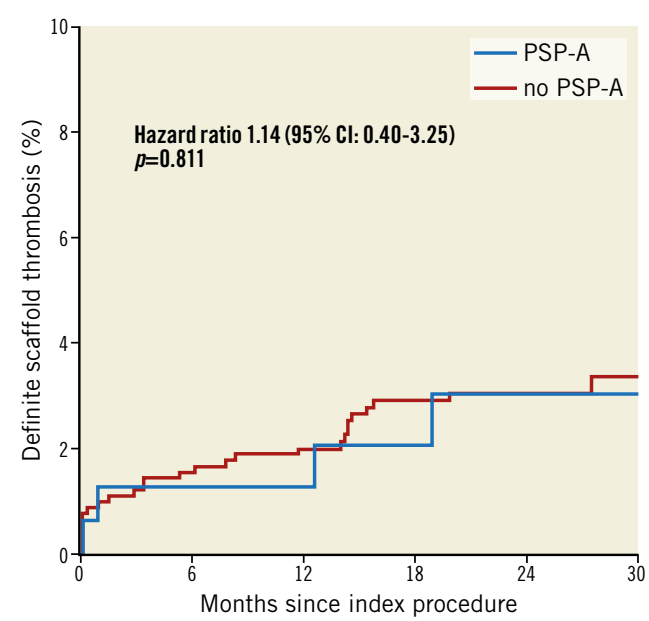

No. at risk

$\begin{array}{lllllll}\text { PSP-A } & 158 & 155 & 133 & 102 & 65 & 22\end{array}$

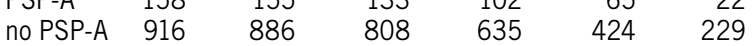

B

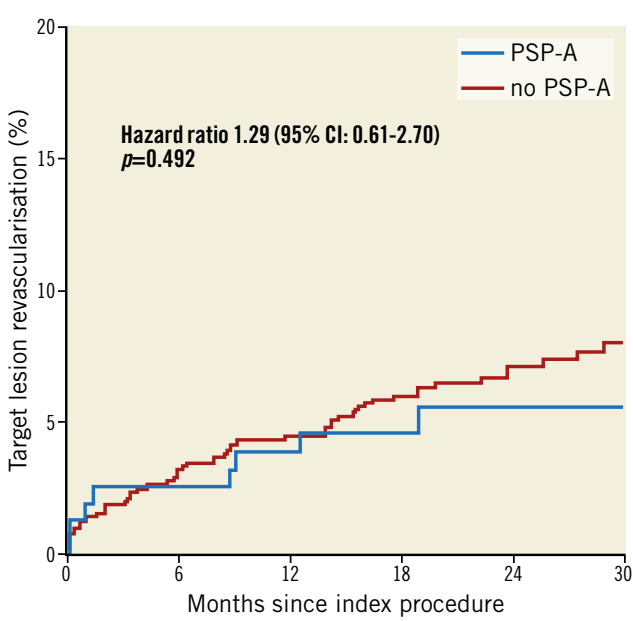

No. at risk

$\begin{array}{lllllll}\text { PSP-A } & 158 & 153 & 131 & 100 & 64 & 32\end{array}$

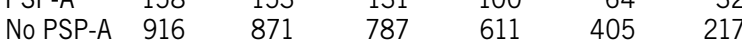

Figure 2. Event rates of definite scaffold thrombosis $(A)$ and target lesion revascularisation $(B)$ in PSP-A or no PSP-A treated lesions. CI: confidence interval; PSP-A: predilatation performed, all scaffolds correctly sized, post-dilatation correctly performed

Figure 3, Supplementary Figure 4). There were four cases of TLR not associated with ScT. Details of the five cases of ScT in implantations meeting any PSP criteria are shown in Table 5.

\section{Discussion}

The main findings of our analysis are:

1) We found no relationship between scaffold sizing or post-dilatation and the rate of ScT or TLR.

2) The definition for scaffold sizing in PSP score models was cumbersome in lesions treated with multiple scaffolds. We applied three different definitions, and we found discrepancies in PSP scoring in 17 of 1,074 lesions.

3) We found four cases of definite ScT occurring in 158 PSP-A treated lesions compared with 27 cases in 916 non-PSP-A treated lesions, with similar KM estimates of $3.0 \%$ and $4.1 \%$, respectively. In addition, there were four more cases of TLR in PSP-A treated lesions, and 35 in non-PSP-A treated lesions.

When the analysis was restricted to lesions treated with a single scaffold, we found three cases of definite ScT in PSP-treated lesions, with similar KM estimates of $2.9 \%$ and $3.3 \%$, respectively. 
A

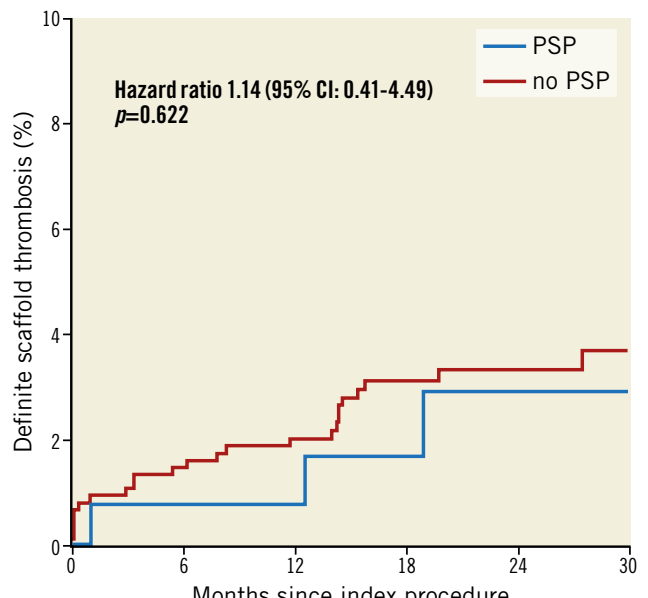

No. at risk

$\begin{array}{lllllll}\text { PSP } & 131 & 129 & 110 & 82 & 51 & 17\end{array}$
B

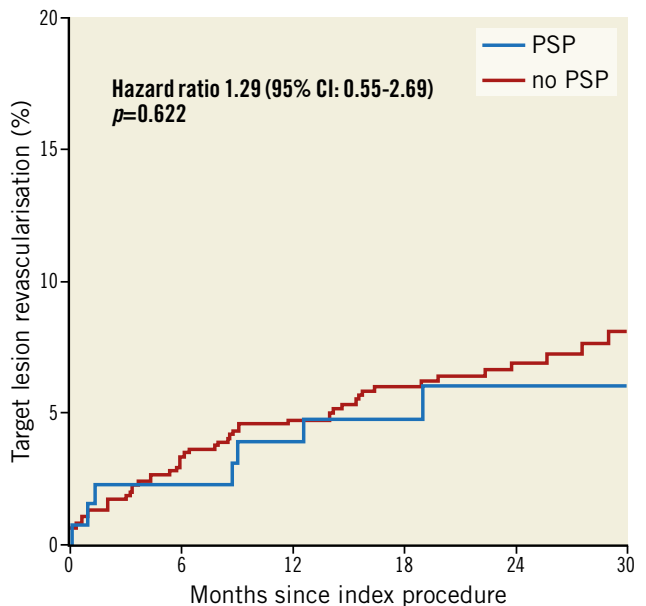

No. at risk

$\begin{array}{lllllll}\text { PSP } & 131 & 127 & 108 & 80 & 50 & 17\end{array}$

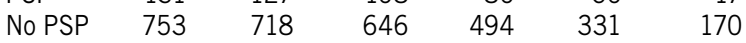

Figure 3. Event rates of definite scaffold thrombosis (A) and target lesion revascularisation (B) in PSP or no PSP treated lesions in the single scaffold per lesion model. CI: confidence interval; PSP: predilatation performed, scaffold correctly sized, post-dilatation correctly performed

Table 5. Details of the five cases of scaffold thrombosis meeting any PSP criterion.

\begin{tabular}{|c|c|c|c|c|c|c|c|c|c|c|c|}
\hline Patient & $\begin{array}{l}\text { Lesion } \\
\quad \#\end{array}$ & $\begin{array}{c}\text { Lesion } \\
\text { location } \\
\text { (segment) }\end{array}$ & $\begin{array}{l}\text { Ref diam } \\
(\mathrm{mm})\end{array}$ & $\begin{array}{c}\# \\
\text { scaffolds }\end{array}$ & Diam 1 & Diam 2 & Diam 3 & $\begin{array}{l}\text { Lesion } \\
\text { PSP }\end{array}$ & Reason no PSP & ScT" & $\begin{array}{c}\text { Time } \\
\text { (days) }\end{array}$ \\
\hline \multirow{2}{*}{1} & 1 & $\operatorname{LAD}(6)$ & 2.8792 & 1 & 3.0 & & & Yes & & Yes & 29 \\
\hline & 2 & RCA (2-3) & 2.2611 & 3 & 3.0 & 2.5 & 2.5 & No & Inadequate sizing & & \\
\hline 2 & 1 & RCA (1-2) & 3.3207 & 2 & 3.5 & 3.5 & & Yes & & Yes & 6 \\
\hline \multirow{2}{*}{3} & 1 & RCA (2) & 3.4658 & 1 & 3.5 & & & Yes & & Yes & 376 \\
\hline & 2 & RCA (3) & 3.0908 & 1 & 3.0 & & & No & No post-dilatation & & \\
\hline \multirow{3}{*}{4} & 1 & RCA (1) & 3.5181 & 1 & 3.5 & & & Yes & & Yes & 567 \\
\hline & 2 & $\mathrm{RCx}(13)$ & 2.2420 & 2 & 3.0 & 3.0 & & No & Inadequate sizing & & \\
\hline & 3 & $\mathrm{RCx}(11)$ & $\mathrm{N} / \mathrm{A}$ & 1 & 3.0 & & & $N / A$ & & & \\
\hline $5^{*}$ & 1 & $\operatorname{LAD}(6)$ & 3.1137 & 2 & 3.5 & 3.0 & & Yes & & Yes & 4 \\
\hline
\end{tabular}

* Lesion 1 in patient 5 only met PSP-S criteria, all other lesions which were treated PSP met PSP-A, PSP-S and PSP-M criteria. " $A$ All scaffold thromboses underwent target lesion revascularisation. PSP: predilatation, sizing, post-dilatation; ScT: scaffold thrombosis

The Absorb BVS has several limitations over metallic DES, such as transparency to X-ray, lower radial and tensile strength, increased strut width and thickness and limited expansion abilities. These limitations require the Absorb BVS to be implanted in a meticulous fashion ${ }^{12}$. Absorb-specific implantation strategies have been proposed to improve the safety and clinical outcomes of patients treated with the Absorb BVS. In the GHOST-EU registry, a specific scaffold implantation strategy predicted the patientlevel one-year device-oriented composite endpoint ${ }^{13}$.

The GHOST-EU registry and the AIDA trial included a high-risk population with a high prevalence of multivessel disease, overlapping scaffolds, and multiple scaffolds per lesion ${ }^{11,14}$. Assessment of PSP sizing in lesions treated with multiple (overlapping) scaffolds is uncharted territory and has yet to be defined. Herein, we analysed PSP scaffold sizing in lesions treated with multiple scaffolds in three different ways (PSP-A, PSP-S and PSP-M). These models provided different PSP scores in a number of lesions. Nevertheless, none of these models showed any predictive value for the occurrence of ScT or TLR.

The recently published "pooled ABSORB PSP analysis" showed that vessel sizing and operator technique were strongly associated with Absorb BVS-related outcomes during three-year follow-up ${ }^{15}$. This analysis used an ad hoc definition for appropriate sizing based on vessel diameter only and ignored the scaffold to vessel diameter ratio, and its potential mismatch. Avoiding scaffold and vessel mismatch is associated with less frequent ischaemia-driven TLR, whereas scaffold oversizing in small coronary vessels may be associated with higher rates of MACE at one-year follow-up ${ }^{16}$. In our analysis, we have applied the conventional definition of scaffold sizing ${ }^{13,17}$. In AIDA, inappropriate sizing was the major reason for not meeting PSP criteria (94\%). If we had applied the pooled ABSORB PSP definition of sizing, 
we would have identified $79.6 \%$ of AIDA Absorb-treated lesions as appropriately sized. This percentage is in stark contrast with the $19.6 \%$ appropriately sized lesions in AIDA under the conventional definition of scaffold sizing. In the pooled ABSORB PSP analysis, optimal predilatation required "balloon to core laboratory-derived reference vessel diameter ratio $\geq 1: 1$ and optimal post-dilatation required post-dilatation with a non-compliant balloon at $\geq 18$ atm and larger than the nominal scaffold diameter, but not by $>0.5 \mathrm{~mm}$ larger". We note that the predilatation and post-dilatation criteria in the "pooled ABSORB PSP analysis" are more stringent than ours, in contrast with the criterion for sizing, which is much less stringent. Only 72 of 1,074 AIDA lesions satisfied the PSP criteria of the pooled ABSORB PSP analysis. We did not observe a relationship between the aggregate PSP according to this definition, and its individual components of aggressive predilatation and aggressive post-dilatation, and the subsequent risk of TLR and ScT (Supplementary Figure 5-Supplementary Figure 7).

PSP is a lesion-specific implantation characteristic. Therefore, we present lesion-oriented outcomes. Notably, we found five cases of ScT that occurred in PSP-treated lesions, of which three occurred in patients with multiple lesion PCI (Table 5). All three patients would have been classified as not meeting PSP criteria because the other lesion(s) were not PSP. A per-patient analysis assigns ScT occurring in PSP-treated lesions to non-PSP-treated patients. This observation shows that classifying patients as meeting or not meeting PSP criteria, with subsequent per-patient outcome analyses, might lead to incorrect conclusions. It explains the discrepancy between our findings and the patient-level analyses reported in the pooled ABSORB PSP and GHOST-EU cohorts.

The main reason for not meeting PSP criteria in our study was inadequate scaffold sizing, mainly due to oversizing. Accurate sizing is particularly problematic in long lesions in tapered vessels because the Absorb BVS cannot be expanded more than $0.5 \mathrm{~mm}$ above the nominal size. The lack of relationship between the PSP score and the individual components of scaffold sizing and postdilatation, and the risk of ScT or TLR implies that operator technique cannot surmount the sizing problems due to the expansion limits of the device. Although the Absorb BVS is not available anymore, these new insights provided by our study can be useful for the development of the next generation of devices with broader expansion limits and better tensile strength, potentially resolving the scaffold sizing issue ${ }^{18}$.

\section{Limitations}

This analysis has several limitations. First, with only 158 PSP and 916 non-PSP lesions the analysis is statistically underpowered. Second, our analysis provides only limited information on the relationship between PSP implantation and the risk of long-term ScT and TLR. Third, as post-dilatation was not mandated in the study protocol, lesions which received post-dilatation might have been lesions with the greatest \% residual stenosis after scaffold implantation, and therefore potential bias in this analysis might have been introduced. Fourth, OCT and QCA after predilatation were not performed, as in many other published PSP analyses. Therefore, we cannot distinguish between successful and unsuccessful predilatation.

\section{Conclusions}

In this AIDA substudy, lesions that underwent scaffold implantation according to an optimised Absorb BVS implantation technique stratified by PSP score showed numerically similar rates of ScT and TLR. The major reason for not meeting PSP criteria was inappropriate sizing. The lack of relationship between the PSP score, predilatation, correct scaffold sizing, or post-dilatation and the risk of ScT or TLR indicates that operator technique cannot surmount the sizing problems due to the expansion limits of the Absorb BVS.

\section{Impact on daily practice}

In AIDA, lesions that underwent scaffold implantation according to an optimised Absorb BVS implantation technique stratified by PSP score did not have lower rates of ScT and TLR. The lack of a relationship between the PSP score and the individual components of scaffold sizing and post-dilatation, and the risk of ScT or TLR suggests that operator technique cannot surmount the sizing problems due to the expansion limits of the current-generation device. Although the Absorb BVS is not commercially available anymore, these new insights provided by our study could be useful for the development of the next generation of devices with broader expansion limits and better tensile strength, potentially resolving the scaffold sizing issue.

\section{Guest Editors}

This paper was guest edited by Adnan Kastrati, MD; Deutsches Herzzentrum, Munich, Germany, and Alec Vahanian, MD, PhD; Department of Cardiology, Hôpital Bichat-Claude Bernard and University Paris VII, Paris, France.

\section{Funding}

The AIDA trial was supported by an unrestricted education grant from Abbott Vascular.

\section{Conflict of interest statement}

The AMC Heart Center received an educational research grant from Abbott Vascular for the AIDA trial. J. Wykrzykowska receives consultancy fees and research grants from Abbott Vascular. J. Henriques receives research grants from Abbott Vascular. J. Piek is a member of the Medical Advisory Board of Abbott Vascular. J. Tijssen served on the DSMB of the early ABSORB trials, including ABSORB II. The other authors have no conflicts of interest to declare. The Guest Editor Adnan Kastrati has no conflicts of interest to declare. The Guest Editor Alec Vahanian is a consultant for Edwards Lifesciences. 


\section{References}

1. Kereiakes DJ, Onuma Y, Serruys PW, Stone GW. Bioresorbable Vascular Scaffolds for Coronary Revascularization. Circulation. 2016;134:168-82.

2. Kimura T, Kozuma K, Tanabe K, Nakamura S, Yamane M, Muramatsu T, Saito S, Yajima J, Hagiwara N, Mitsudo K, Popma JJ, Serruys PW, Onuma Y, Ying S, Cao S, Staehr P, Cheong WF, Kusano H, Stone GW; ABSORB Japan Investigators. A randomized trial evaluating everolimus-eluting Absorb bioresorbable scaffolds vs. everolimus-eluting metallic stents in patients with coronary artery disease: ABSORB Japan. Eur Heart J. 2015;36:3332-42.

3. Serruys PW, Chevalier B, Dudek D, Cequier A, Carrie D, Iniguez A, Dominici M, van der Schaaf RJ, Haude M, Wasungu L, Veldhof S, Peng L, Staehr P, Grundeken MJ, Ishibashi Y, GarciaGarcia HM, Onuma Y. A bioresorbable everolimus-eluting scaffold versus a metallic everolimus-eluting stent for ischaemic heart disease caused by de-novo native coronary artery lesions (ABSORB II): an interim 1-year analysis of clinical and procedural secondary outcomes from a randomised controlled trial. Lancet. 2015;385:43-54.

4. Stone GW, Gao R, Kimura T, Kereiakes DJ, Ellis SG, Onuma Y, Cheong WF, Jones-McMeans J, Su X, Zhang Z, Serruys PW. 1-year outcomes with the Absorb bioresorbable scaffold in patients with coronary artery disease: a patient-level, pooled meta-analysis. Lancet. 2016;387:1277-89.

5. Onuma Y, Sotomi Y, Shiomi H, Ozaki Y, Namiki A, Yasuda S, Ueno T, Ando K, Furuya J, Igarashi K, Kozuma K, Tanabe K, Kusano H, Rapoza R, Popma JJ, Stone GW, Simonton C, Serruys PW, Kimura T. Two-year clinical, angiographic, and serial optical coherence tomographic follow-up after implantation of an everolimus-eluting bioresorbable scaffold and an everolimus-eluting metallic stent: insights from the randomised ABSORB Japan trial. EuroIntervention. 2016;12:1090-101.

6. Serruys PW, Chevalier B, Sotomi Y, Cequier A, Carrie D, Piek JJ, Van Boven AJ, Dominici M, Dudek D, McClean D, Helqvist S, Haude M, Reith S, de Sousa Almeida M, Campo G, Iniguez $\mathrm{A}$, Sabaté $\mathrm{M}$, Windecker $\mathrm{S}$, Onuma Y. Comparison of an everolimus-eluting bioresorbable scaffold with an everolimus-eluting metallic stent for the treatment of coronary artery stenosis (ABSORB II): a 3 year, randomised, controlled, single-blind, multicentre clinical trial. Lancet. 2016;388:2479-91.

7. Collet C, Asano T, Miyazaki Y, Tenekecioglu E, Katagiri Y, Sotomi Y, Cavalcante R, de Winter RJ, Kimura T, Gao R, Puricel S, Cook S, Capodanno D, Onuma Y, Serruys PW. Late thrombotic events after bioresorbable scaffold implantation: a systematic review and meta-analysis of randomized clinical trials. Eur Heart J. 2017;38:2559-66.

8. Elias J, van Dongen IM, Kraak RP, Tijssen RYG, Claessen B, Tijssen JGP, de Winter RJ, Piek JJ, Wykrzykowska JJ, Henriques JPS. Mid-term and long-term safety and efficacy of bioresorbable vascular scaffolds versus metallic everolimus-eluting stents in coronary artery disease: A weighted meta-analysis of seven randomised controlled trials including 5577 patients. Neth Heart J. 2017;25: 429-38
9. de Boer SP, Lenzen MJ, Oemrawsingh RM, Simsek C, Duckers HJ, van der Giessen WJ, Serruys PW, Boersma E. Evaluating the 'all-comers' design: a comparison of participants in two 'all-comers' PCI trials with non-participants. Eur Heart J. 2011;32:2161-7.

10. Woudstra P, Grundeken MJ, Kraak RP, Hassell ME, Arkenbout EK, Baan J Jr, Vis MM, Koch KT, Tijssen JG, Piek JJ, de Winter RJ, Henriques JP, Wykrzykowska JJ. Amsterdam Investigator-initiateD Absorb strategy all-comers trial (AIDA trial): a clinical evaluation comparing the efficacy and performance of ABSORB everolimus-eluting bioresorbable vascular scaffold strategy vs the XIENCE family (XIENCE PRIME or XIENCE Xpedition) everolimus-eluting coronary stent strategy in the treatment of coronary lesions in consecutive all-comers: rationale and study design. Am Heart J. 2014;167:133-40.

11. Wykrzykowska JJ, Kraak RP, Hofma SH, van der Schaaf RJ, Arkenbout EK, IJsselmuiden AJ, Elias J, van Dongen IM, Tijssen RYG, Koch KT, Baan J Jr, Vis MM, de Winter RJ, Piek JJ, Tijssen JGP, Henriques JPS; AIDA Investigators. Bioresorbable Scaffolds versus Metallic Stents in Routine PCI. $N$ Engl J Med. 2017;376:2319-28.

12. Serruys PW, Onuma Y. Dmax for sizing, PSP-1, PSP-2, PSP-3 or OCT guidance: interventionalist's jargon or indispensable implantation techniques for short- and long-term outcomes of Absorb BRS? EuroIntervention. 2017;12:2047-56.

13. Ortega-Paz L, Capodanno D, Gori T, Nef H, Latib A, Caramanno G, Di Mario C, Naber C, Lesiak M, Capranzano P, Wiebe J, Mehilli J, Araszkiewicz A, Pyxaras S, Mattesini A, Geraci S, Naganuma T, Colombo A, Munzel T, Sabaté M, Tamburino C, Brugaletta S. Predilation, sizing and post-dilation scoring in patients undergoing everolimus-eluting bioresorbable scaffold implantation for prediction of cardiac adverse events: development and internal validation of the PSP score. EuroIntervention. 2017;12:2110-7.

14. Capodanno D, Gori T, Nef H, Latib A, Mehilli J, Lesiak M, Caramanno G, Naber C, Di Mario C, Colombo A, Capranzano P, Wiebe J, Araszkiewicz A, Geraci S, Pyxaras S, Mattesini A, Naganuma T, Munzel T, Tamburino C. Percutaneous coronary intervention with everolimus-eluting bioresorbable vascular scaffolds in routine clinical practice: early and midterm outcomes from the European multicentre GHOST-EU registry. EuroIntervention. 2015;10:1144-53.

15. Stone GW, Abizaid A, Onuma Y, Seth A, Gao R, Ormiston J, Kimura T, Chevalier B, Ben-Yehuda O, Dressler O, McAndrew T, Ellis SG, Kereiakes DJ, Serruys PW. Effect of Technique on Outcomes Following Bioresorbable Vascular Scaffold Implantation: Analysis From the ABSORB Trials. J Am Coll Cardiol. 2017;70: 2863-74.

16. Ishibashi Y, Nakatani S, Sotomi Y, Suwannasom P, Grundeken MJ, Garcia-Garcia HM, Bartorelli AL, Whitbourn R, Chevalier B, Abizaid A, Ormiston JA, Rapoza RJ, Veldhof S, Onuma Y, Serruys PW. Relation Between Bioresorbable Scaffold Sizing Using QCA-Dmax and Clinical Outcomes at 1 Year in 1,232 
Patients From 3 Study Cohorts (ABSORB Cohort B ABSORB EXTEND, and ABSORB II). JACC Cardiovasc Interv. 2015;8:1715-26.

17. Tamburino C, Latib A, van Geuns RJ, Sabate M, Mehilli J, Gori T, Achenbach S, Alvarez MP, Nef H, Lesiak M, Di Mario C, Colombo A, Naber CK, Caramanno G, Capranzano P, Brugaletta S, Geraci S, Araszkiewicz A, Mattesini A, Pyxaras SA, Rzeszutko L, Depukat R, Diletti R, Boone E, Capodanno D, Dudek D. Contemporary practice and technical aspects in coronary intervention with bioresorbable scaffolds: a European perspective. EuroIntervention. 2015;11:45-52.

18. Sotomi Y, Onuma Y, Collet C, Tenekecioglu E, Virmani R, Kleiman NS, Serruys PW. Bioresorbable Scaffold: The Emerging Reality and Future Directions. Circ Res. 2017;120:1341-52.

\section{Supplementary data}

Supplementary Figure 1. Lesion-oriented outcomes of the individual component of scaffold sizing in PSP-A or no PSP-A treated lesions.
Supplementary Figure 2. Lesion-oriented outcomes of the individual component of post-dilatation in PSP-A or no PSP-A treated lesions.

Supplementary Figure 3. Lesion-oriented outcomes of the individual component of scaffold sizing in lesions treated with a single scaffold.

Supplementary Figure 4. Lesion-oriented outcomes of the individual component of post-dilatation in lesions treated with a single scaffold.

Supplementary Figure 5. Lesion-oriented outcomes by PSP-PA or no PSP-PA treated lesions.

Supplementary Figure 6. Lesion-oriented outcomes by aggressive predilatation.

Supplementary Figure 7. Lesion-oriented outcomes by aggressive post-dilatation.

The supplementary data are published online at:

http://www.pcronline.com/

eurointervention/137th issue/77 


\section{Supplementary data}

Supplementary Figure 1. Lesion-oriented outcomes of the individual component of scaffold sizing in PSP-A or no PSP-A treated lesions. Shown is the event rate of definite scaffold thrombosis (A) or target lesion revascularisation (B) of the individual component of correct scaffold sizing in the PSP-A model. CI: confidence interval; PSP-A: predilatation; all scaffolds correctly sized; post-dilatation correctly performed

A.

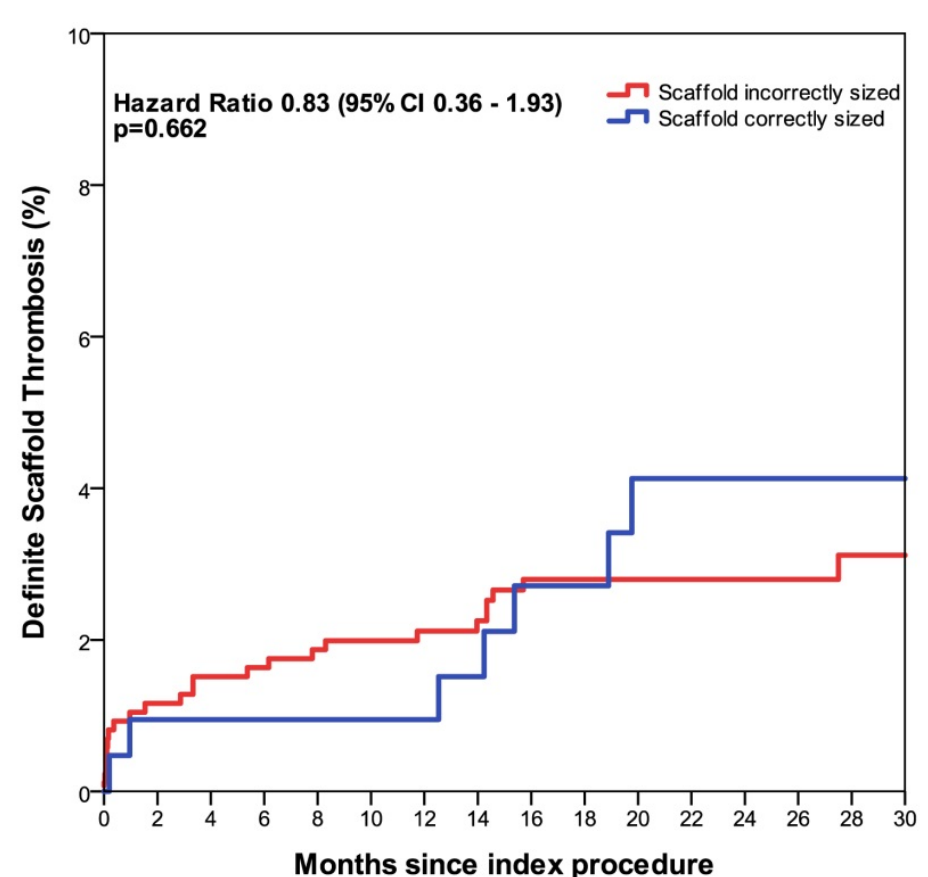

No. at risk

Incorrect sizin

Correct sizing

863
211

833
208

761
180
B.

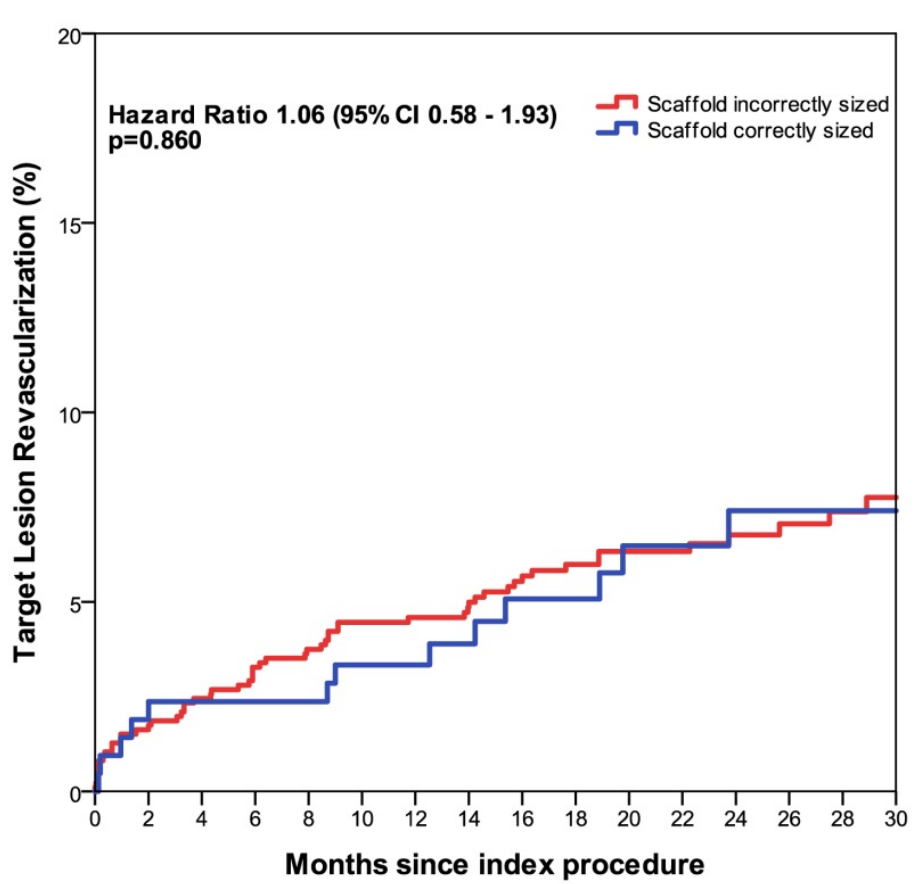

No. at risk

Incorrect sizin

21

833

761
180

571
140 
Supplementary Figure 2. Lesion-oriented outcomes of the individual component of post-dilatation in PSP-A or no PSP-A treated lesions. Shown is the event rate of definite scaffold thrombosis (A) or target lesion revascularisation (B) of the individual component of correct post-dilatation in the PSP-A model. Cl: confidence interval; PSP-A: predilatation; all scaffolds correctly sized; post-dilatation correctly performed

A.

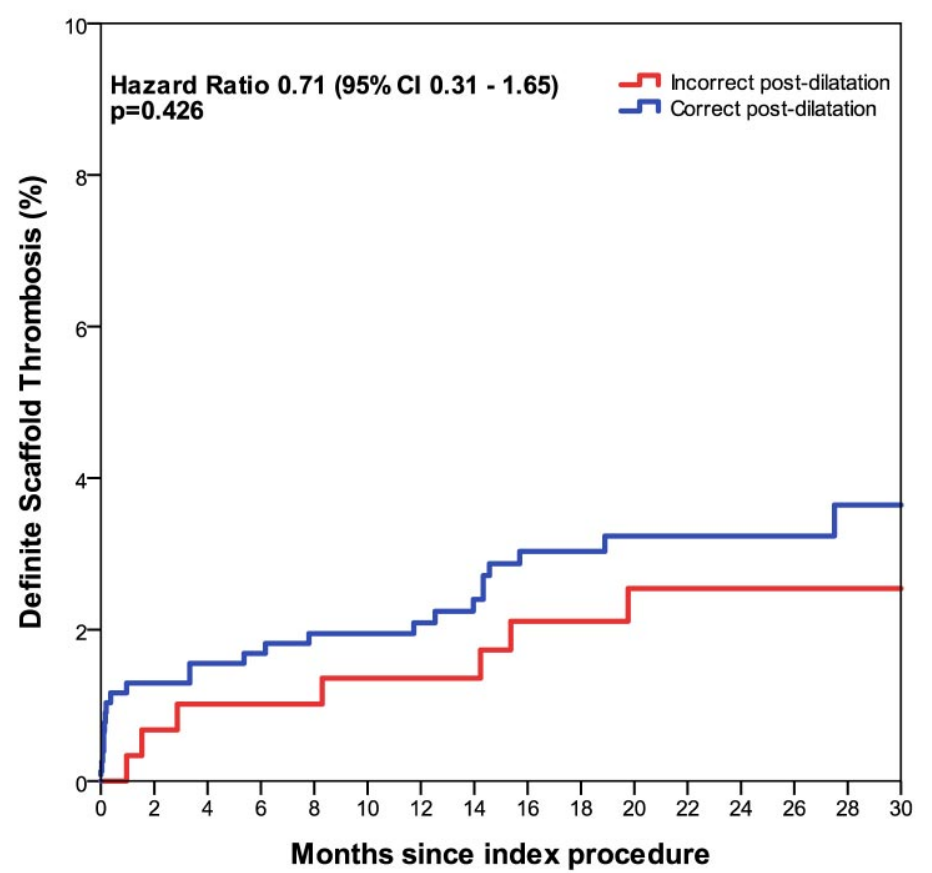

B.

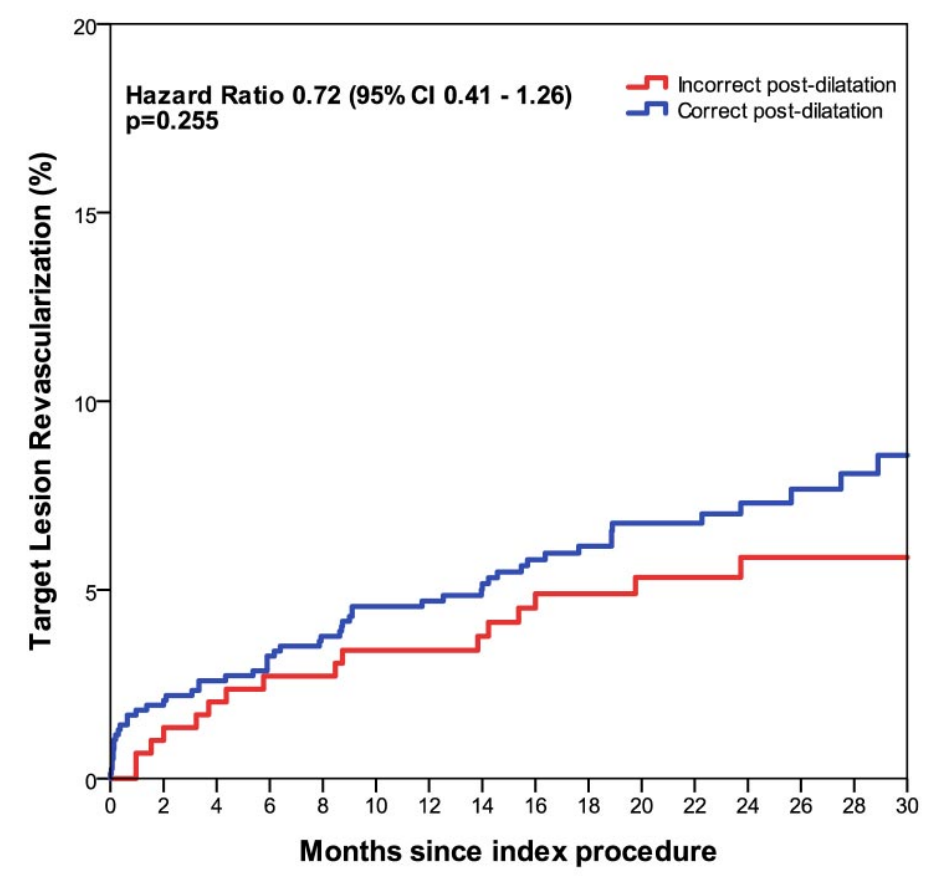

No. at risk Incorrect post-dilatation 374
289
752
239
495

\section{No. at risk} Correct post-dilatation 
Supplementary Figure 3. Lesion-oriented outcomes of the individual component of scaffold sizing in lesions treated with a single scaffold. Shown is the event rate of definite scaffold thrombosis (A) or target lesion revascularisation (B) of the individual component of correct scaffold sizing in the single scaffold per lesion model. Cl: confidence interval

A.

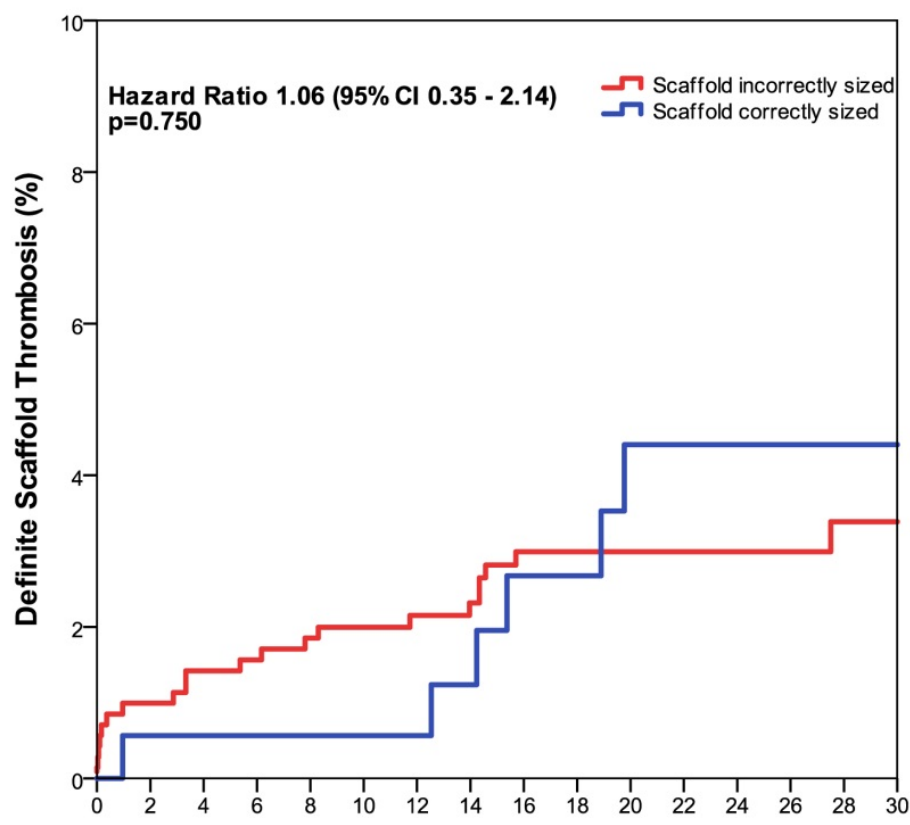

Months since index procedure

No. at risk Incorrect sizin
B.

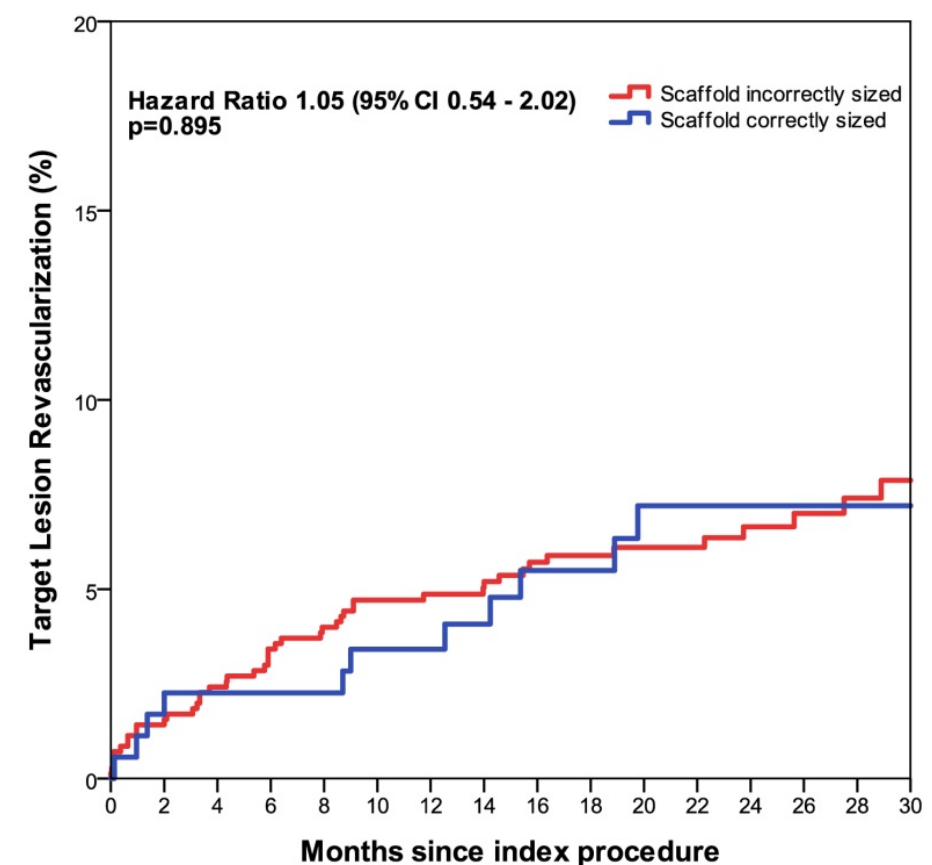

No. at risk Incorrect sizin
Correct sizing

Months since index procedure 
Supplementary Figure 4. Lesion-oriented outcomes of the individual component of post-dilatation in lesions treated with a single scaffold. Shown is the event rate of definite scaffold thrombosis (A) or target lesion revascularisation (B) of the individual component of correct post-dilatation in the single scaffold per lesion model. Cl: confidence interval

A.

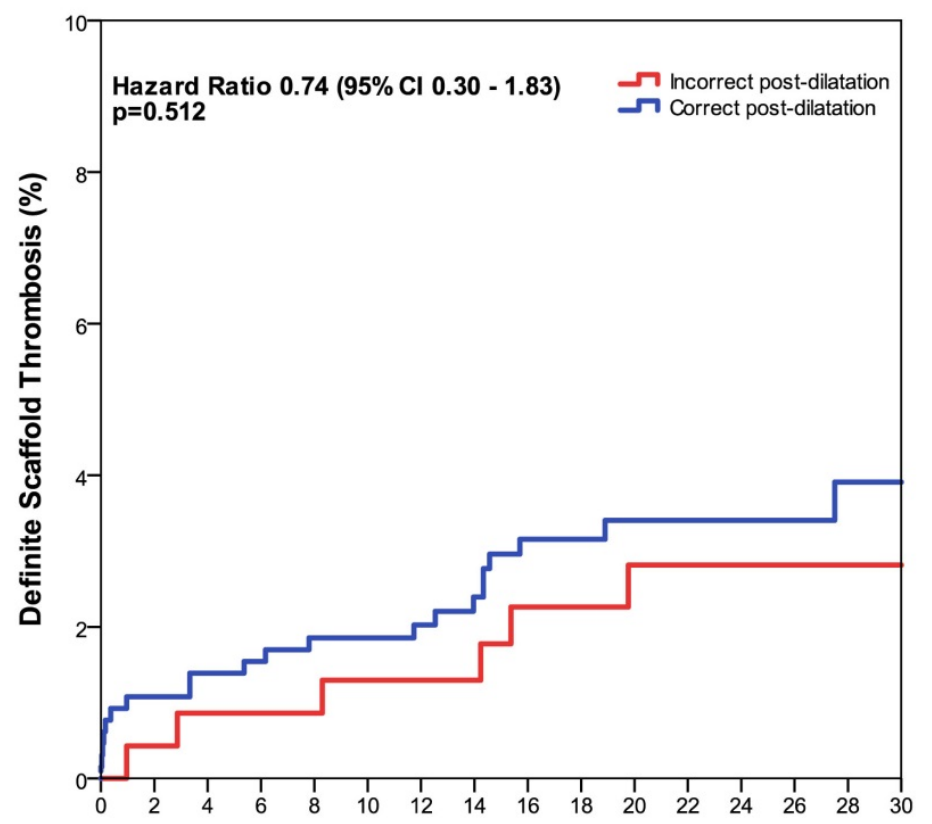

Months since index procedure

\section{No. at risk}

Correct post-dilatation 234

Correct post-dilatation 650
227

214
561

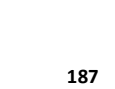

133
265
B.

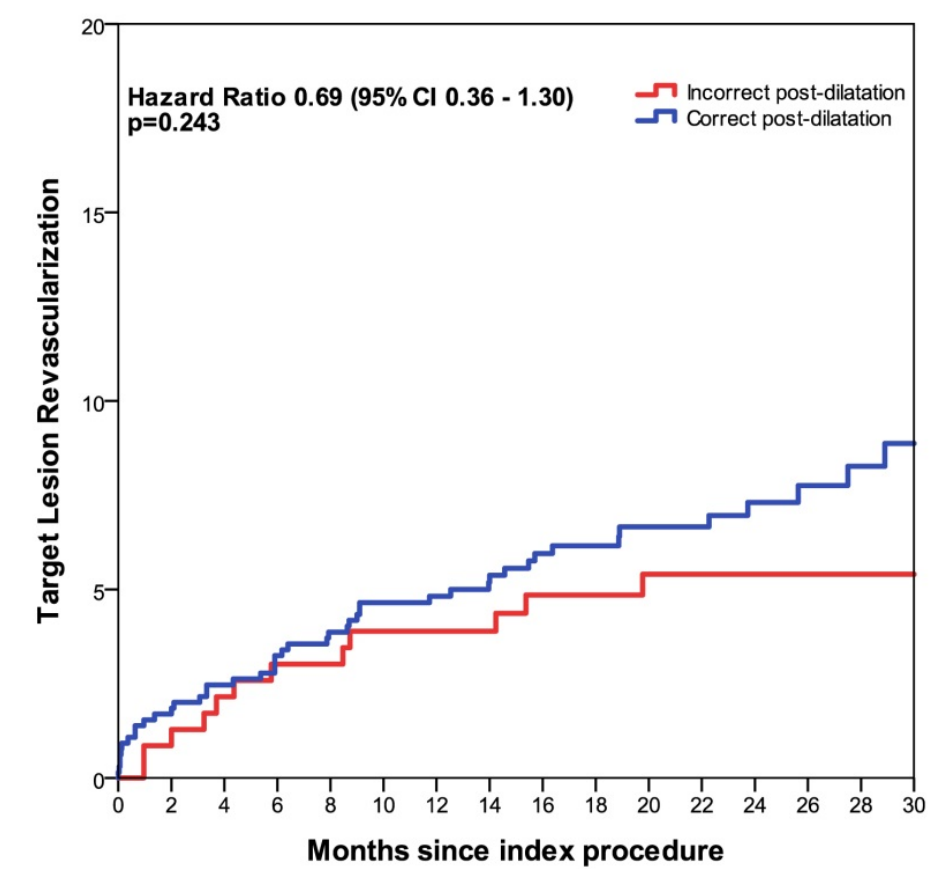

Months since index procedure

No. at risk

Incorrect post-dilatation
Correct post-dilatation
234
649
208
547 
Supplementary Figure 5. Lesion-oriented outcomes by PSP-PA or no PSP-PA treated lesions. Shown is the event rate of definite scaffold thrombosis (A) or target lesion revascularisation $(B)$ according to the PSP definition of the "pooled ABSORB analysis" (PSP-PA). PSP-PA = (1) predilatation performed with a maximum dilatation balloon diameter $\geq$ reference vessel diameter; (2) vessel correctly sized (reference vessel diameter $\geq 2.25$ or $\leq 3.75$; and (3) post-dilatation performed at $\geq 18$

atmospheres with a non-compliant balloon with a nominal diameter equal to or greater than that of the widest scaffold, but no greater than $0.5 \mathrm{~mm}$ over the nominal scaffold diameter. $\mathrm{Cl}$ : confidence interval

A.

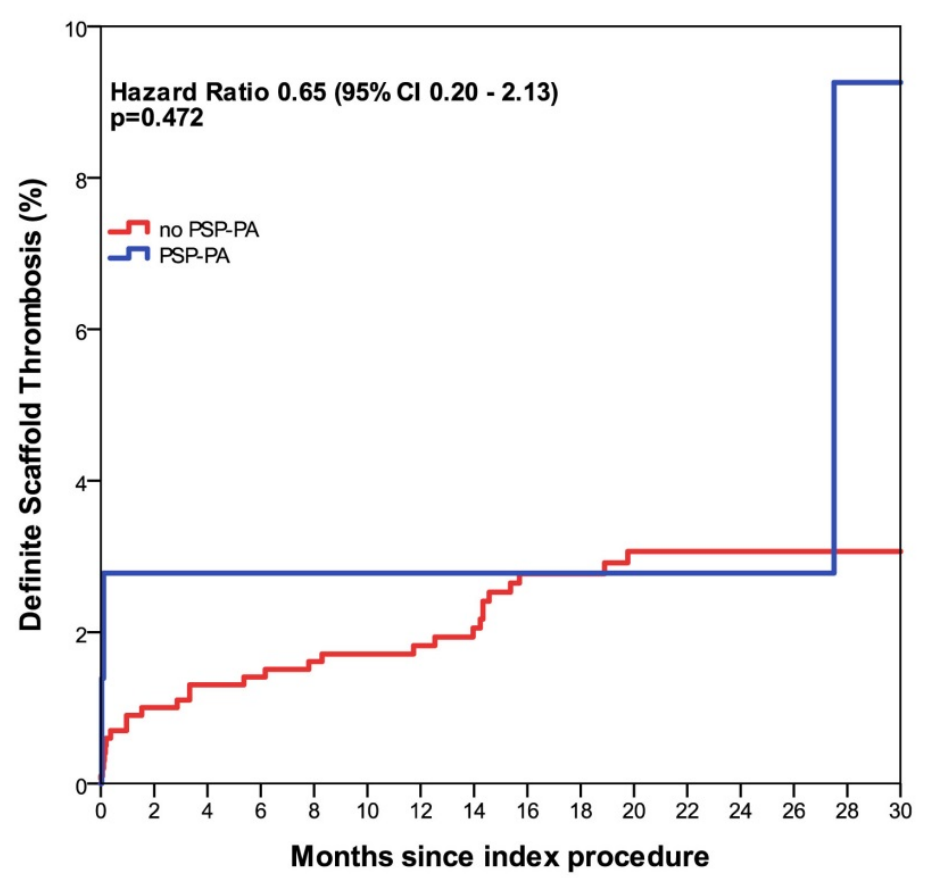

No. at risk no PSP-PA
PSP-PA 1002
971
70

880
62
691
43
464
26
B.

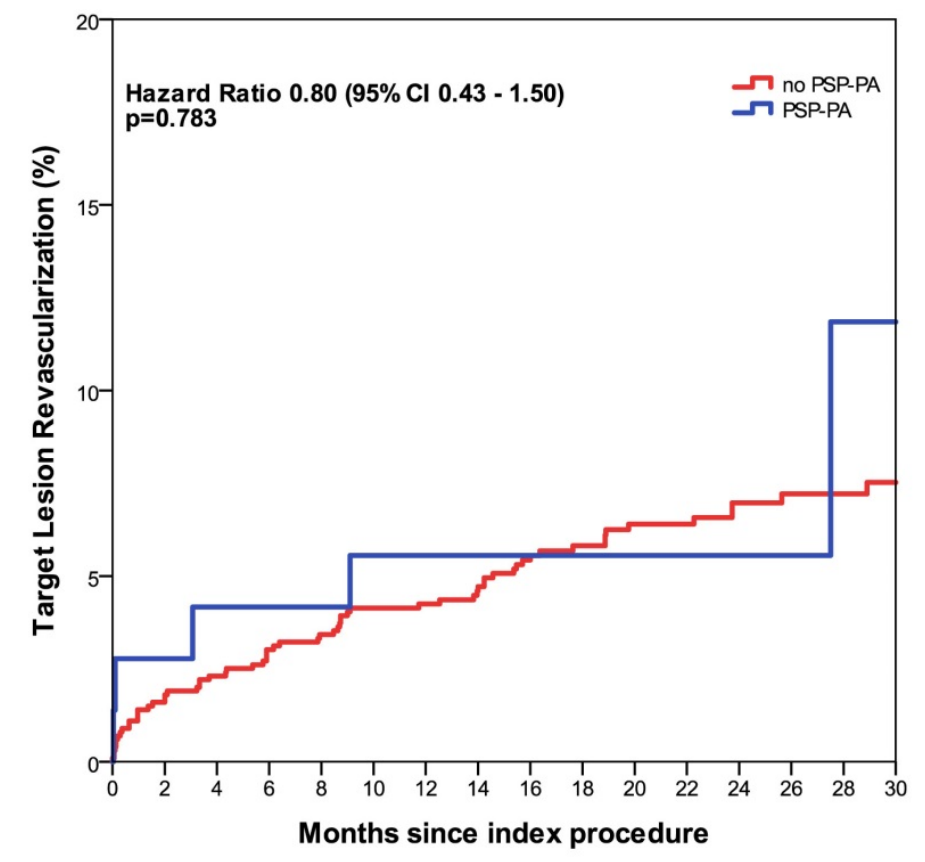

No. at risk
no PSPP.PA no PSP-PA
PSPPPA 1002
72
955
69

859
60 $\begin{array}{rr}670 & 444 \\ 41 & 25\end{array}$

230
9 
Supplementary Figure 6. Lesion-oriented outcomes by aggressive predilatation. Shown is the event rate of definite scaffold thrombosis (A) or target lesion revascularisation (B) by aggressive predilatation as defined in the pooled ABSORB PSP analysis. Aggressive predilatation: predilatation performed with a maximum dilatation balloon diameter $\geq$ reference vessel diameter; $\mathrm{Cl}$ : confidence interval

A.

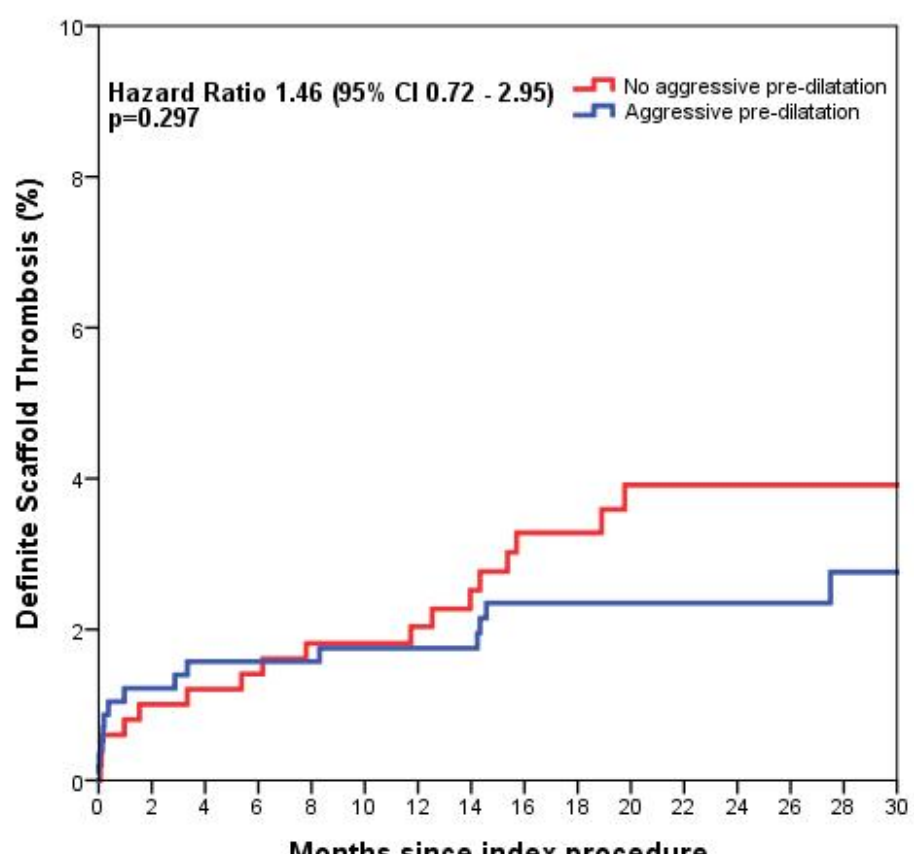

Months since index procedure
B.

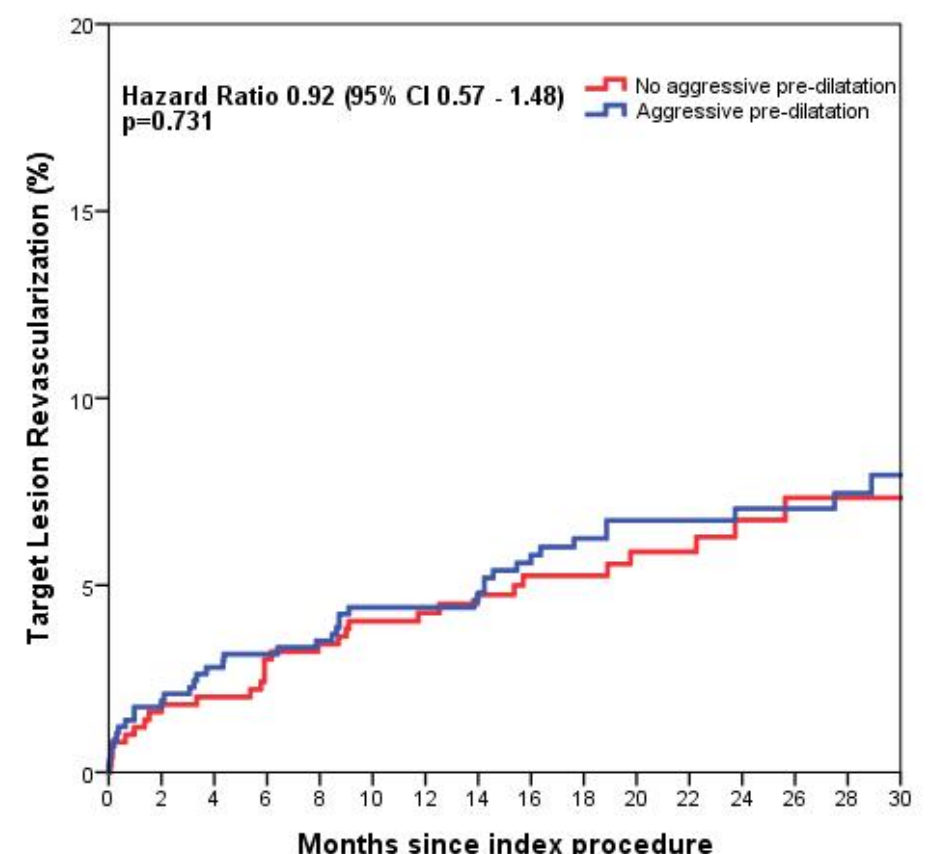

Months since index procedure

\section{No. at risk}

o aggressive pre-dilatation 498
488
553
320
414
No. at risk Aggressive pre-dilatation 498
419
500

313
427

191 
Supplementary Figure 7. Lesion-oriented outcomes by aggressive post-dilatation. Shown is the event rate of definite scaffold thrombosis (A) or target lesion revascularisation (B) by aggressive post-dilatation as defined in the pooled ABSORB PSP analysis. Aggressive post-dilatation: post-dilatation performed on $\geq 18$ atm, with a non-compliant balloon with a nominal diameter equal to or greater than that of the widest scaffold, but no greater than $0.5 \mathrm{~mm}$ over the nominal scaffold diameter; $\mathrm{Cl}$ : confidence interval

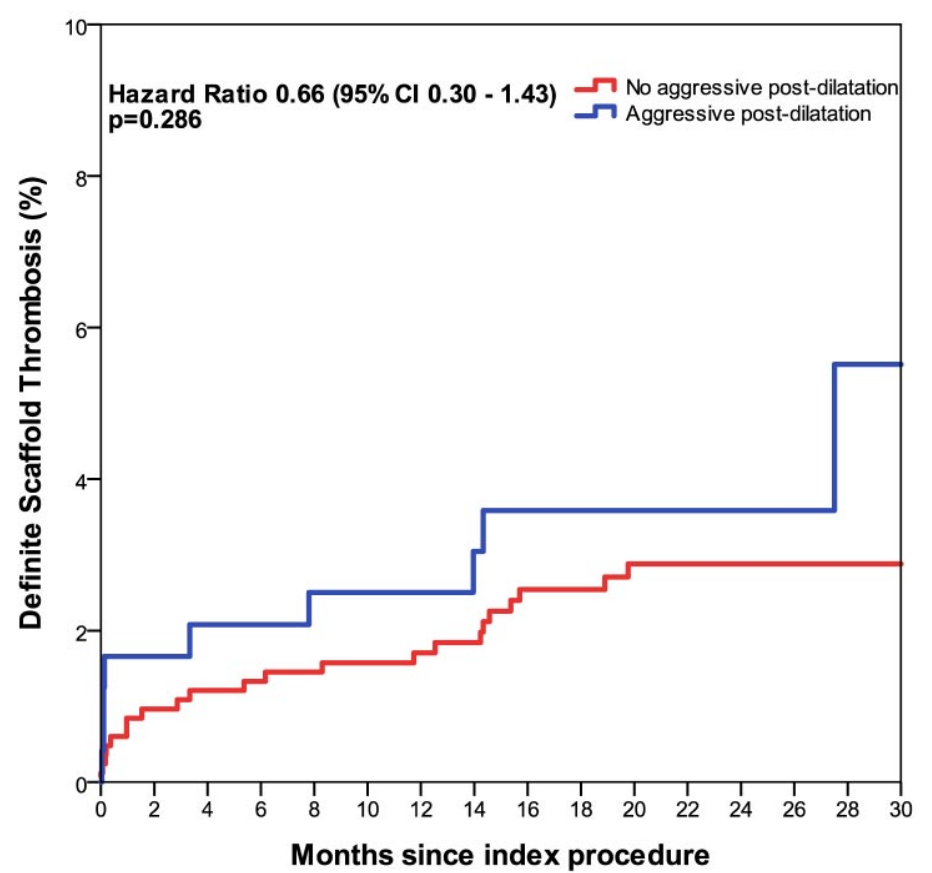

No. at risk

Nost-dilatation 833

807

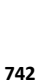

742
199

599
135
B.

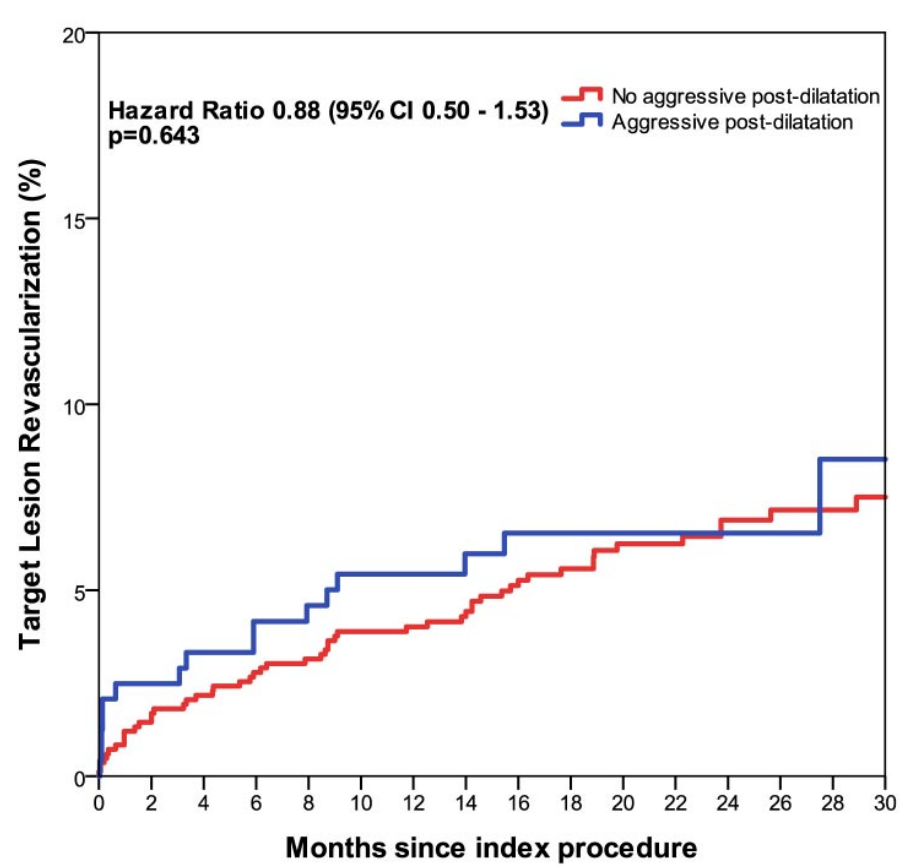

No. at risk

No aggressive post-dilatation 833

795
229

725
193

582
129

395

211 